\title{
Avaliação do Consumo de Silagens de Sorgo Tratadas com Amônia Anidra e, ou, Sulfeto de Sódio na Alimentação de Novilhas $3 / 4$ Indubrazil/Holandês
}

\author{
Aureliano José Vieira Pires ${ }^{1}$, Rasmo Garcia ${ }^{2}$, Alexandre Lima de Souza ${ }^{3}$, Fabiano Ferreira da Silva ${ }^{4}$, \\ Cristina Mattos Veloso ${ }^{4}$, Gláucon Cezar Cardoso ${ }^{5}$, Tatiana Neres de Oliveira ${ }^{6}$, Polyana Albino Silva ${ }^{7}$
}

\begin{abstract}
RESUMO - Foram utilizadas oito novilhas 3/4 Indubrasil/Holandês de peso médio 160 kg, distribuídas em dois quadrados latinos 4 x 4, em quatro períodos de 21 dias, sendo 15 dias de adaptação e seis dias de coletas de amostras. Os animais receberam dieta na proporção de 60:40 de volumoso:concentrado (base da MS), sendo o volumoso utilizado a silagem de sorgo, ensilada com teor de MS em torno de $30 \%$, e o concentrado à base de milho e farelo de soja, contendo 15,6\% de proteína bruta. Os tratamentos foram classificados em: T1 - controle (silagem sem aditivo), T2 - silagem tratada com 2,5\% de sulfeto de sódio, T3 - silagem tratada com 2,5\% de amônia anidra e T4 - silagem tratada com 2,5\% de sulfeto de sódio + 2,5\% de amônia anidra, todos com base na MS, sob período de armazenamento de seis meses. Foram estudados o consumo de matéria seca (MS), consumo de proteína bruta (PB), consumo de fibra em detergente neutro (FDN) e consumo de fibra em detergente ácido (FDA), diário, em percentagem do peso vivo e em função do peso metabólico. Verificou-se efeito para as variáveis estudadas, em que os valores de consumo mais elevados foram para a dieta com silagem de sorgo tratada com amônia, enquanto o sulfeto de sódio não mostrou efeito. Estes valores mostram a eficiência da amônia anidra na ação dos constituintes da parede celular, promovendo, dessa forma, melhoria no consumo.
\end{abstract}

Palavras-chave: amonização, conservação, consumo

\section{Sorghum Silage Treated with Anhydrous Ammonia and, or, Sodium Sulfide Added to the Diet for $3 / 4$ Indubrazil/Holstein Steers}

\begin{abstract}
Eight 3/4 Indubrazil/Holstein heifers, averaging $160 \mathrm{~kg}$, were assigned to $4 \mathrm{x} 4$ latin squares, during four periods of 21 days, 15 days of adaptation and six days of samples collection. The animals were fed a diet with 60:40 roughage:concentrate (DM basis), using as roughage sorghum silage, ensiled with DM content of 30\%, and as concentrate, corn and soybean meal, with $15.6 \%$ crude protein. The treatments were: T1 - control (silage without additive), T2 - silage treated with 2.5\% sodium sulfide, T3 - silage treated with $2.5 \%$ anhydrous ammonia and T4 - silage treated with $2.5 \%$ sodium sulfide $+2.5 \%$ anhydrous ammonia, all in dry matter basis, using storage time of six months for all treatments. Dry matter (DM), crude protein (CP), neutral detergent fiber (NDF) and acid detergent fiber (ADF) daily intakes, in percentage of live weight and metabolic weight, were studied. It was verified effect for all studied variables, where the higher intake values were observed for the sorghum silage treated with ammonia, while sodium sulfide did not show any effect. These values show the anhydrous ammonia efficiency on the action of cell wall constituents, resulting in higher intake.
\end{abstract}

Key Words: ammoniation, conservation, intake

\section{Introdução}

Para o uso de silagens na alimentação de ruminantes, deve-se levar em consideração que, durante o processo de ensilagem, a proteína da forragem é hidrolisada por enzimas proteolíticas endógenas e microrganismos, o que acarreta aumento da fração nitrogenada não protéica, que pode não ser adequadamente utilizada, devido à sua rápida solubilização e à falta de sincronização com a liberação de energia (Fontanelli et al., 2002). Concordando com este fato, Petit (1994) relata que o desempenho de animais recebendo silagem é limitado pelo consumo de proteína não degradada no rúmen.

Dessa forma, fontes de nitrogênio não protéico podem ser adicionadas para suprir estas exigências, dentre elas a amônia anidra e a uréia, que, além de fornecer nitrogênio não protéico, pode alterar a com-

\footnotetext{
${ }^{1}$ Professor Adjunto DTRA/UESB, Itapetinga, BA, Pós-Doutorando da FAPESB. E.mail: aupires@uesb.br

${ }_{2}^{2}$ Pesquisador do CNPq, DZO/UFV, Viçosa, MG.

${ }^{3}$ Doutor em Zootecnia/UFV, Viçosa, MG.

${ }^{4}$ Professor Adjunto DTRA/UESB, Itapetinga, BA

${ }^{5}$ Mestre em Zootecnia pela UFV, Viçosa, MG.

${ }^{6}$ Doutoranda em Zootecnia/UFRPE, Recife, PE.

${ }^{7}$ Mestranda em Zootecnia/UFV, Viçosa, MG.
} 
posição de forragens.

A amonização de forragens tem sido utilizada com o intuito de conservar forragens com alto teor de umidade, como silagens, e também para a melhoria do valor nutritivo de volumosos em geral por meio do fornecimento de nitrogênio não protéico, por redução na fração da fibra em detergente neutro (FDN) e pelo aumento na digestibilidade do material tratado.

As formas mais comuns de amonização são via amônia anidra $\left(\mathrm{NH}_{3}\right)$ ou uréia $\left(\mathrm{NH}_{2} \mathrm{COONH}_{2}\right)$. Existe também o hidróxido de amônio $\left(\mathrm{NH}_{4} \mathrm{OH}\right)$, entretanto, é pouco utilizado em função do difícil manuseio. A amônia anidra possui teor elevado de nitrogênio (82\%), sendo encontrada, normalmente, no estado líquido sob baixas temperaturas ou pressões relativamente altas, enquanto a uréia possui em torno de $44 \%$ de nitrogênio, é encontrada na forma sólida, necessitando de umidade e presença da enzima urease para que possa produzir $2 \mathrm{NH}_{3}+\mathrm{CO}_{2}$, para cada molécula de uréia.

Fatores como dose aplicada, fonte de nitrogênio, material tratado, período de tratamento e teor de umidade influenciam o resultado da amonização.

A dose de nitrogênio aplicada está em torno de 1,0 a 1,5\% de amônia anidra e de 3,0 a 5,0\% de uréia, com base na matéria seca, quando o objetivo for conservação, e de 2,0 a 4,0\% de amônia anidra e de 7,0 a $8,0 \%$ de uréia quando o objetivo for a melhoria na qualidade do material com baixa digestibilidade.

Rocha et al. (2001), estudando diferentes níveis de uréia (0, 2, 4 e 6\%) no tratamento de silagem de capim-elefante por 60 dias de tratamento, não verificaram diferenças para os constituintes da parede celular, entretanto, para a DIVMS os valores encontrados foram de 41,90; 52,30; 56,01 e 55,02\%, respectivamente para as doses citadas, mostrando o efeito de níveis crescentes e melhoria da qualidade da silagem.

Utilizando bagaço e ponta de cana-de-açúcar, tratados com amônia anidra, uréia e sulfato de amônio, Gesualdi et al. (2001) relataram que a amônia anidra promoveu redução da FDN e da celulose do bagaço, e decréscimo da hemicelulose da ponta de cana. Os autores relataram ainda que a amonização com o sulfato de amônio demonstrou maior eficiência na redução na fração de FDA, principalmente para a ponta de cana.

Pires (2000), utilizando bagaço de cana-de-açúcar tratado com sulfeto de sódio e, ou, amônia anidra verificaram reduções nas frações de FDN e de hemicelulose, em que os valores encontrados para os tratamentos, controle, 2,5\% de $\mathrm{Na}_{2} \mathrm{~S}, 4 \% \mathrm{de}_{3}$, e
2,5\% de $\mathrm{Na}_{2} \mathrm{~S}$ mais $4 \%$ de $\mathrm{NH}_{3}$ foram de 94,7; 93,4; 75,8 e 75,8\% para FDN e de 33,1; 29,9; 19,4 e 19,9\% para hemicelulose. A ação da amônia anidra, segundo o autor, promoveu melhoria na degradação destas frações, o que resultou em aumento na DIVMS, com valores de 32,1; 32,9; 59,8 e 58,1\%, respectivamente.

Ao tratarem silagem de pés de milho, contendo $40 \%$ de matéria seca, com 6,6\% de uréia, ou 6,5\% de uréia mais $5 \%$ de $\mathrm{SO}_{2}$, Fahmy \& Klopfenstein (1994) encontraram valores crescentes para a proteína bruta, que variaram de $5,2 \%$ para a silagem sem tratamento, $13,4 \%$ para a silagem tratada com $6,6 \%$ de uréia, e $17,1 \%$ para a silagem tratada com ou $6,6 \%$ de uréia mais $5 \%$ de $\mathrm{SO}_{2}$, o que corresponde a aumentos de 156 e $227 \%$, respectivamente, para os tratamentos com uréia e uréia mais $\mathrm{SO}_{2}$, comprovando, dessa forma, maior retenção de nitrogênio ao se adicionar uma fonte de enxofre.

Objetivou-se com o experimento avaliar o consumo de matéria seca (MS), de proteína bruta (PB), de fibra em detergente neutro (FDN) e de fibra em detergente ácido (FDA) por novilhas alimentadas com silagens de sorgo tratadas com amônia anidra e, ou, sulfeto de sódio.

\section{Material e Métodos}

O experimento foi conduzido na Universidade Estadual do Sudoeste da Bahia, no Campus Juvino Oliveira, na cidade de Itapetinga, BA. Foram utilizadas oito novilhas 3/4 Indubrasil/Holanadês de peso médio $160 \mathrm{~kg}$, distribuídas em dois quadrados latinos 4 x 4, em quatro períodos de 21 dias, sendo 15 dias de adaptação e seis de coletas de amostras.

Os animais receberam dieta na proporção de 60:40 de volumoso:concentrado (base da MS), ad libitum, sendo permitida uma sobra diária em torno de $10 \%$ do fornecido. O volumoso utilizado foi a silagem de sorgo com teor de MS de $30 \%$, e o concentrado à base de milho e farelo de soja, contendo $15,6 \%$ de proteína bruta.

Os tratamentos foram classificados em: T1 controle (silagem sem aditivo), T2 - silagem tratada com 2,5\% de sulfeto de sódio, T3 - silagem tratada com 2,5\% de amônia anidra e T4 - silagem tratada com 2,5\% de sulfeto de sódio $+2,5 \%$ de amônia anidra, sendo todos tratamento com base da MS do sorgo (30\%).

A composição química do concentrado e do sorgo cortado pode ser verificada na Tabela 1 . 
Foram utilizados quatro silos de superfície, com aproximadamente 5 toneladas cada, acondicionados sobre lona no solo, para evitar perdas de amônia anidra. A amônia anidra foi aplicada (2,5\%) por meio de dois canos de pvc, perfurados e com uma extremidade vedada para melhor difusão da amônia. Foram utilizados botijões de $80 \mathrm{~kg}$ de amônia, os quais foram colocados em cima de uma balança para que desta forma, por diferença de peso, registrasse a quantidade de amônia anidra aplicada.

Para o sulfeto de sódio (2,5\%), o material foi diluído em água na proporção 3:1 (água:sulfeto) e aplicado com regador e homogeneizado em seguida. Para todos os tratamentos, o período de armazenamento foi de seis meses.

Após seis meses, foram abertos os silos, iniciando-se o fornecimento aos animais, onde se estudou o consumo de matéria seca (MS), consumo de proteína bruta (PB), consumo de fibra em detergente neutro (FDN), e consumo de fibra em detergente ácido (FDA), diário expressos em kg, em percentagem do peso vivo e em função do peso metabólico. Amostras de volumosos foram coletadas no momento do fornecimento dos animais. Para as silagens que receberam tratamento com amônia, o material foi retirado e fornecido somente após 24 horas, para que não houvesse rejeição pelos animais, em função do forte cheiro de amônia anidra.

As análises de volumoso, de concentrado e de sobras foram realizadas conforme procedimentos

Tabela 1 - Composição química do concentrado e do sorgo utilizados no experimento

Table 1 - Chemical composition of concentrate and roughage of experiment

\begin{tabular}{lcc}
\hline $\begin{array}{l}\text { Item } \\
\text { Item }\end{array}$ & $\begin{array}{c}\text { Concentrado } \\
\text { Concentrate }\end{array}$ & $\begin{array}{c}\text { Sorgo picado } \\
\text { Roughage }\end{array}$ \\
\hline $\mathrm{MS}$ & 88,0 & 30,15 \\
$\mathrm{DM}$ & 15,6 & 8,67 \\
$\mathrm{~PB}^{1}$ & 13,2 & 65,48 \\
$\mathrm{CP}^{1}$ & & \\
$\mathrm{FDN}^{1}$ & 6,0 & 40,38 \\
$N \mathrm{~F}^{1}$ & & 30,57 \\
$\mathrm{FDA}^{1}$ & 4,0 & 25,10 \\
$\mathrm{ADF}$ & & \\
Celulose & 1 & 9,27 \\
Cellulose & & \\
$\begin{array}{l}\text { Hemicelulose } \\
\text { Hemicellulose }\end{array}$ & 7,2 & \\
Lignina $^{1}$ & 2,0 & \\
Ligin $^{1}$ & &
\end{tabular}

${ }^{1}$ Base da MS (Base DM). descritos por Silva (1990).

Os resultados foram interpretados, estatisticamente, por meio, de teste Tukey, a 5\% de probabilidade, utilizando-se Sistema de Análises Estatísticas e Genéticas, SAEG versão 8.0 (UFV, 1998).

\section{Resultados e Discussão}

Após abertura dos silos não foram observadas perdas por fungos, através da observação visual, para as silagens tratadas com $\mathrm{NH}_{3}$, enquanto que para a silagem sem tratamento ou tratada com $\mathrm{Na}_{2} \mathrm{~S}$, verificou-se visualmente a presença de fungos em algumas partes.

Utilizando bagaço e ponta de cana-de-açúcar tratados com amônia anidra, uréia e sulfato de amônia, Gesualdi et al. (2001) verificaram conservação dos subprodutos sendo que os benefícios resultantes dos tratamentos persistiram até 48 dias para o bagaço e até 28 dias para a ponta de cana, demonstrando a capacidade de conservação quando fontes de nitrogênio não protéico são adicionados à forragens com alta umidade. Conservação da quirera de milho com alta umidade (25\%) foi também relatada por Pires et al. (1999), quando utilizaram 2 e $3 \%$ de $\mathrm{NH}_{3}$. Os autores relataram ainda que para o tratamento controle ( $\operatorname{sem~} \mathrm{NH}_{3}$ ) e para o tratamento utilizando $1 \%$ de $\mathrm{NH}_{3}$, sinais de fungos visíveis foram observados, enquanto para os demais tratamentos (2 e $3 \%$ de $\mathrm{NH}_{3}$ ) os materiais permaneceram por 28 dias de aeração não apresentaram sinais visíveis de fungos.

A composição química das silagens pode ser verificada na Tabela 2. Observa-se teores de MS constantes para os tratamentos, enquanto para PB os valores aumentaram para as silagens tratadas com $\mathrm{NH}_{3}$. Os aumentos foram de 124,8 e $128,1 \%$, respectivamente, para a silagem com $\mathrm{NH}_{3}$, e $\mathrm{NH}_{3}$ mais $\mathrm{Na}_{2} \mathrm{~S}$, quando comparadas ao controle. Neste caso, o $\mathrm{Na}_{2} \mathrm{~S}$, não afetou o teor de PB. Estes dados concordam com os de Neiva et al. (1998) que ao amonizarem silagem e rolão de milho, tendo como fonte a amônia anidra, verificaram um aumento de 204\%, independentemente do volumoso. Estes aumentos, relatados, são em função da amônia anidra fornecer nitrogênio não protéico (NNP) e este permanecer em grande parte, mesmo após abertura de silos. Este nitrogênio é de extrema importância, uma vez que deverá ser utilizado por microrganismos do rúmen para síntese protéica.

Na Tabela 2, podem-se verificar valores menores 
de FDN e hemicelulose, quando amostras de volumoso dos quatro silos foram coletadas, correspondendo ao controle, 2,5\% $\mathrm{Na}_{2} \mathrm{~S}, 2,5 \% \mathrm{NH}_{3}$, e $2,5 \% \mathrm{Na}_{2} \mathrm{~S}+$ $2,5 \% \mathrm{NH}_{3}$, respectivamente sugerindo como na maioria dos trabalhos (Reis et al., 1997, Sarmento et al., 1999), redução destes componentes quando forragens são amonizadas. E também como a maioria dos trabalhos (Fahmy \& Klopfenstein, 1994; Madrid et al., 1997; Pires et al., 1999), FDA, celulose e lignina normalmente não se alteram (Tabela 2).

Na Tabela 3, são apresentados os valores obtidos para o consumo médio diário de matéria seca (MS) e de proteína bruta $(\mathrm{PB})$ para os diferentes tratamentos. Verificou-se efeito $(\mathrm{P}<0,01)$ para consumo diário de MS e de PB para os tratamentos, sendo verificados para a $\mathrm{NH}_{3}$ maiores valores, independentemente da adição do $\mathrm{Na}_{2} \mathrm{~S}$.

Apesar de não terem sido submetidos a análises estatísticas, os valores apresentados na Tabela 2 sugerem que a amônia anidra possui efeito de redução do conteúdo de parede celular e aumento no teor de $\mathrm{PB}$, o que pode ter contribuído para melhoria no consumo de MS e de PB.

Resultados semelhantes quanto à variação no consumo MS e de PB foram encontrados por Pires (2000) quando utilizou bagaço de cana-de-açúcar, tratados com, $\mathrm{NH}_{3}$, e, ou $\mathrm{Na}_{2} \mathrm{~S}$, e fornecidos à novilhas $1 \frac{1}{2}$ Holandês/Indubrasil, com peso vivo médio de $230 \mathrm{~kg}$. Os resultados para consumo diário de MS foram de 1,92, 2,06, 2,46 e 2,42\% PV, e 76,72, 82,40,
100,18 e 97,44, e para consumo diário de PB de 0,25, $0,26,0,45$ e $0,47 \%$ PV, e 9,87, 10,17, 18,15 e 18,80 $\mathrm{g} / \mathrm{kgPV}^{0,75}$ para os tratamentos controle, $\mathrm{Na}_{2} \mathrm{~S}, \mathrm{NH}_{3}$, e $\mathrm{Na}_{2} \mathrm{~S}, \mathrm{NH}_{3}$. Segundo o autor o aumento no consumo tanto de MS quanto de PB, foi devido ao aumento da digestibilidade do material tratado e do aumento no teor de PB promovidos pela amônia anidra.

Damasceno et al. (2000) ao fornecerem a ovinos castrados, palha de arroz amonizada com 5\% de uréia, nos níveis de oferta de 1,5, 3,0, 4,5, 6,0 e 7,5\% do peso vivo, verificaram que o consumo potencial máximo de matéria seca e da matéria seca digestível foi de 2,5 e 1,4\% PV, e que decréscimos consideráveis no consumo de MS e de matéria seca digestível ocorreram em níveis de oferta abaixo de 3,0 e 4,3\% do peso vivo, respectivamente.

Utilizando também silagem de sorgo, porém, como suplementação protéica a farinha de penas hidrolisadas, o farelo de soja e o farelo de soja tratado com formaldeído, na alimentação de bovinos de corte em crescimento (156 kg de peso vivo), Fontanelli et al. (2002) verificaram consumos de matéria seca, independentemente da fonte protéica, semelhantes aos do presente trabalho, os valores encontrados foram de 4,43, 4,74 e 4,85 kg/dia, 2,54, 2,68 e 2,66\% do peso vivo, e 90,8, 97,5 e 97,0 g/ $\mathrm{kgPV}^{0,75}$, respectivamente para os tratamentos citados. Entretanto, para o consumo diário de proteína bruta, os autores encontraram valores de 598, 614 e 624 g/dia, e de 13, 13 e $12,9 \mathrm{~g} / \mathrm{kgPV}^{0,75}$, respectivamente, para a farinha

Tabela 2 - Composição química das silagens de sorgo tratadas ou não com amônia anidra $\left(\mathrm{NH}_{3}\right)$ e, ou, sulfeto de sódio $\left(\mathrm{Na}_{2} \mathrm{~S}\right)$

Table 2 - Chemical composition of sorghum silage treated or not with anhydrous ammonia $\left(\mathrm{NH}_{3}\right)$ and, or, sodium sulphide ( $\left.\mathrm{Na}_{2} \mathrm{~S}\right)$

\begin{tabular}{|c|c|c|c|c|}
\hline \multirow[t]{2}{*}{$\begin{array}{l}\text { Item } \\
\text { Item }\end{array}$} & \multicolumn{4}{|c|}{$\begin{array}{l}\text { Tratamento (base da MS) } \\
\text { Treatment (DM basis) }\end{array}$} \\
\hline & $\begin{array}{l}\text { Controle } \\
\text { Control }\end{array}$ & $2,5 \% \mathrm{Na}_{2} \mathrm{~S}$ & $2,5 \% \mathrm{NH}_{3}$ & $2,5 \% \mathrm{Na}_{2} \mathrm{~S}+2,5 \% \mathrm{NH}_{3}$ \\
\hline $\begin{array}{l}\text { MS } \\
D M\end{array}$ & 28,33 & 28,28 & 31,75 & 30,18 \\
\hline $\begin{array}{l}\mathrm{PB} \\
C P\end{array}$ & 8,13 & 8,20 & 18,28 & 18,55 \\
\hline $\begin{array}{l}\text { FDN } \\
N D F\end{array}$ & 66,88 & 66,78 & 62,75 & 62,73 \\
\hline $\begin{array}{l}\text { FDA } \\
A D F\end{array}$ & 41,00 & 41,23 & 41,40 & 40,85 \\
\hline $\begin{array}{l}\text { Celulose } \\
\text { Cellulose }\end{array}$ & 29,90 & 30,55 & 29,63 & 30,28 \\
\hline $\begin{array}{l}\text { Hemicelulose } \\
\text { Hemicellulose }\end{array}$ & 25,83 & 25,55 & 21,35 & 21,90 \\
\hline $\begin{array}{l}\text { Lignina } \\
\text { Liginin }\end{array}$ & 9,58 & 9,68 & 9,83 & 9,73 \\
\hline
\end{tabular}


de penas hidrolisadas, farelo de soja e farelo de soja tratado com formaldeído. Estes resultados quando comparados aos do presente trabalho, sugerem que ao se utilizar silagem de sorgo tratada com $\mathrm{NH}_{3}$, independentemente do $\mathrm{Na}_{2} \mathrm{~S}$, bovinos em crescimento aumentam o consumo diário de PB (Tabela 3).

Rahal et al. (1997), utilizando palhada de arroz sem tratamento ou tratada com 3\% de uréia em dietas para novilhas com peso médio de $106 \mathrm{~kg}$, verificaram ingestão de matéria orgânica degradável de 2,1 e $2,6 \% \mathrm{PV}$, respectivamente, concordando com dados do presente trabalho.

Independentemente das fontes de $\mathrm{N}$ e dos volumosos amonizados, em geral, observa-se aumento no consumo de matéria seca da ordem de 10 a 20\%, quando comparados aos volumosos que não recebem tratamentos.

Para as variáveis consumo de FDN e FDA, foram verificados efeito $(\mathrm{P}<0,01)$ para os tratamentos, onde se observa maior consumo diário de FDN e de FDA expressos em $\mathrm{kg} / \mathrm{dia}$, \% PV e g/kg/PV ${ }^{0,75}$ para as silagens tratadas com $\mathrm{NH}_{3}$, independentemente do $\mathrm{Na}_{2} \mathrm{~S}$ (Tabela 4). O aumento no consumo pode ser justificado por redução dos teores de FDN e, conforme Fahmy \& Klopfenstein (1994), ocorre expansão da celulose, o que contribui para aumento na DIVMS e, conseqüentemente, maior taxa de passagem.

Aumentos na digestibilidade de FDN, FDA, celulose e hemicelulose foram relatados por Rosa et al. (1998) quando utilizaram fenos de braquiária tratados com uréia e $\mathrm{NH}_{3}$. Os valores médios de aumento encontrados foram de respectivamente de 8,3, 6,4, 11,4 e 7,2\%, quando comparados ao controle. Estes relatos dão subsídios para reafirmar que ocorre aumento no consumo de forragens amonizadas, quando comparadas a materiais não tratados, em razão de haver desestruturação dos constituintes da parede celular, às vezes reduzindo, como é o caso do FDN e hemicelulose, ou mantendo constante, mas aumentando sua digestão como é o caso da FDA e da celulose, promovendo desta forma um maior ataque dos microrganismos ruminais à parede celular. Os resultados do presente trabalho estão de acordo com os obtidos por Pires (2000), que verificou aumentos no consumo de FDN, para novilhas em crescimento, ao utilizar como volumoso o bagaço de cana-deaçúcar tratado com $\mathrm{NH}_{3}$. Os valores foram de 0,84 , 0,97, 1,17 e 1,14 \% PV e 33,37, 38,64, 47,61 e 46,14 g/kgPV0,75, para os tratamentos controle, $\mathrm{Na}_{2} \mathrm{~S}, \mathrm{NH}_{3}$, e $\mathrm{Na}_{2} \mathrm{~S}$ mais $\mathrm{NH}_{3}$.

Tabela 3 - Consumos de matéria seca (MS) e de proteína bruta (PB) por novilhas alimentadas com silagens de sorgo tratadas ou não com amônia anidra $\left(\mathrm{NH}_{3}\right)$ e, ou, sulfeto de sódio $\left(\mathrm{Na}_{2} \mathrm{~S}\right)$

Table 3 - Intake of dry matter (DM) and crude protein $(C P)$ of heifers fed with sorghum silage treated or not with anhydrous ammonia $\left(\mathrm{NH}_{3}\right)$ and, or, sodium sulphide $\left(\mathrm{Na}_{2} \mathrm{~S}\right)$

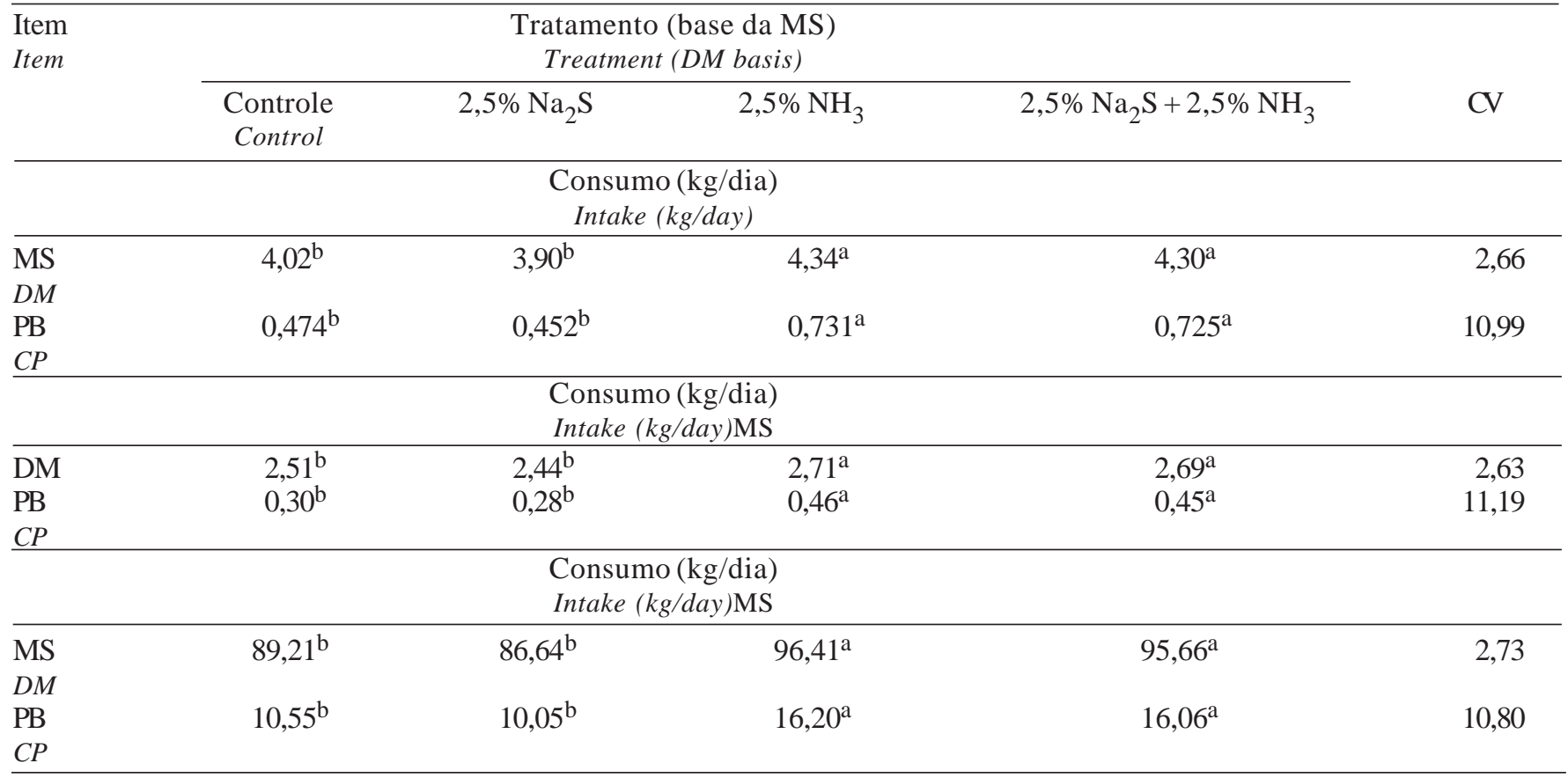

Médias seguidas das mesmas letras, na linha, não diferem $(P>0,05)$ pelo teste Tukey.

Means followed by same letters, in a line, did not differ $(P>.05)$ by Tukey test. 
Tabela 4 - Consumos de fibra em detergente neutro (FDN) e de fibra em detergente ácido (FDA) por novilhas alimentadas com silagens de sorgo tratadas ou não com amônia anidra $\left(\mathrm{NH}_{3}\right)$ e, ou, sulfeto de sódio ( $\mathrm{Na} 2 \mathrm{~S}$ )

Table 4 - Intake of neutral detergent fiber (NDF) and acid neutral fiber (ADF) of heifers fed with sorghum silage treated or not with anhydrous ammonia $\left(\mathrm{NH}_{3}\right)$ and, or, sodium sulphide $\left(\mathrm{Na}_{2} \mathrm{~S}\right)$

\begin{tabular}{|c|c|c|c|c|c|}
\hline \multirow[t]{2}{*}{$\begin{array}{l}\text { Itens } \\
\text { Item }\end{array}$} & \multicolumn{4}{|c|}{$\begin{array}{l}\text { Tratamento (base da MS) } \\
\text { Treatment (DM basis) }\end{array}$} & \multirow[b]{2}{*}{$\mathrm{CV}$} \\
\hline & $\begin{array}{l}\text { Controle } \\
\text { Control }\end{array}$ & $2,5 \% \mathrm{Na}_{2} \mathrm{~S}$ & $2,5 \% \mathrm{NH}_{3}$ & $2,5 \% \mathrm{Na}_{2} \mathrm{~S}+2,5 \% \mathrm{NH}_{3}$ & \\
\hline \multicolumn{6}{|c|}{$\begin{array}{l}\text { Consumo (kg/dia) } \\
\text { Intake (kg/day) }\end{array}$} \\
\hline $\begin{array}{l}\text { FDN } \\
N D F\end{array}$ & $1,57^{\mathrm{b}}$ & $1,50^{\mathrm{b}}$ & $1,89^{\mathrm{a}}$ & $1,80^{\mathrm{a}}$ & 4,26 \\
\hline $\begin{array}{l}\text { FDA } \\
A D F\end{array}$ & $0,93^{b}$ & $0,89^{\mathrm{b}}$ & $1,17^{\mathrm{a}}$ & $1,16^{\mathrm{a}}$ & 5,23 \\
\hline \multicolumn{6}{|c|}{$\begin{array}{l}\text { Consumo (kg/dia) } \\
\text { Intake (kg/day) }\end{array}$} \\
\hline $\begin{array}{l}\text { FDN } \\
N D F\end{array}$ & $0,98^{\mathrm{b}}$ & $0,94^{\mathrm{b}}$ & $1,18^{\mathrm{a}}$ & $1,12^{\mathrm{a}}$ & 4,28 \\
\hline $\begin{array}{l}\text { FDA } \\
A D F\end{array}$ & $0,58^{\mathrm{b}}$ & $0,56^{\mathrm{b}}$ & $0,72^{\mathrm{a}}$ & $0,73^{\mathrm{a}}$ & 4,95 \\
\hline \multicolumn{6}{|c|}{$\begin{array}{l}\text { Consumo (kg/dia) } \\
\text { Intake (kg/day) }\end{array}$} \\
\hline $\begin{array}{l}\text { FDN } \\
N D F\end{array}$ & $34,95^{b}$ & $33,35^{b}$ & $42,06^{\mathrm{a}}$ & $39,93^{a}$ & 4,28 \\
\hline $\begin{array}{l}\text { FDA } \\
A D F\end{array}$ & $20,71^{b}$ & $19,74^{\mathrm{b}}$ & $25,82^{\mathrm{a}}$ & $25,77^{a}$ & 5,06 \\
\hline
\end{tabular}

Médias seguidas das mesmas letras, na linha, não diferem $(P>0,05)$ pelo teste Tukey.

Means followed by same letters, in a line, did not differ $(P>05)$ by Tukey test.

\section{Conclusões}

A amônia anidra provocou alterações na composição química da silagem de sorgo resultando em aumento no consumo diário de MS, PB, FDN e FDA, expressos em kg/dia, em percentagem do peso vivo e em função do peso metabólico, enquanto o sulfeto de sódio não provocou tais alterações, refletindo em valores de consumo semelhantes ao tratamento controle.

\section{Literatura Citada}

DAMASCENO, J.C.; SANTOS, G.T.; CECATO, U. et al. Consumo voluntário e balanço de nitrogênio recebendo palha de arroz amonizada em diferentes níveis de oferta. Revista Brasileira de Zootecnia, v.29, n.4, p.1167-1173, 2000.

FAHMY, S.T.M.; KLOPFENSTEIN, T.J. Treatment with different chemicals and their effects on the digestibility of maize stalks. 2. Intake and in vivo digestibility as affected by chemical treatment and monensin supplementation. Animal Feed Science and Technology, v.45, n.3/4, p.309-16, 1994.

FONTANELLI, R.S.; PRATES, E.R.; RAMOS, P. et al. Suplementação da silagem de sorgo com diferentes fontes de proteína para bovinos de corte. Revista Brasileira de Zootecnia, v.31, n.1, p.183-191, 2002.

GESUALDI, A.C.L.S.; COELHO DA SILVA, J.F.; VASQUEZ, H.M. et al. Efeito da amonização sobre a composição, a retenção de nitrogênio e a conservação do bagaço e da ponta de cana-de-açúcar. Revista Brasileira de Zootecnia, v.30, n.2, p.508-517, 2001.

MADRID, J.; HERNÁNDEZ, F.; PULGAR, M.A. et al. In vivo digestibility of trated and untreated barley straw: results of direct and by-difference digestibility trials. Animal Feed Science and Technology, v.65, p.129-138, 1997.

NEIVA, J.N.M.; GARCIA, R.; VALADARES FILHO, S. C. et al. Características químicas da silagem e do rolão de milho amonizados. Revista Brasileira de Zootecnia, v.27, n.3, p.461-465, 1998.

PETIT, H.V. Forage quality and its factors for production. In: SIMPÓSIO INTERNACIONAL DE PRODUÇÃO DE RUMINANTES, 1994, Maringá. Anais... Maringá: EDUEM, 1994, p.62-79.

PIRES, A.J.V. Bagaço de cana-de-açúcar tratado com amônia anidra e, ou, sulfeto de sódio para novilhas em crescimento. Viçosa, MG: Universidade Federal de Viçosa, 2000. 65p. Tese (Doutorado em Zootecnia) - Universidade Federal de Viçosa, 2000.

PIRES, A.J.V.; GARCIA, R.; CECON, P.R. et al. Amonização da quirera de milho com alta umidade. Revista Brasileira de Zootecnia, v.28, n.6, p.1186-1193, 1999.

RAHAL, A.; SINGH, A.; SINGH, M. Effect of urea treatment and composition on, and prediction of value of rice straw of different cultivars. Animal Feed Science and Technology, v.68, p.165-182, 1997.

REIS, R.A.; RODRIGUES, L.R.A.; PEREIRA, J.R.A. et al. Composição química e digestibilidade de fenos tratados com amônia anidra ou uréia. Revista Brasileira de Zootecnia, v.30, n.3, p.666-673, 2001. 
ROCHA, F.C.; GARCIA, R.; PEREIRA, O.G.P. et al. Níveis de uréia e períodos de amonização sobre o valor nutritivo da silagem de capim-elefante (Pennisetum purpureum Schum) cv. Napier. In: REUNIÃO ANUAL DA SOCIEDADE BRASILEIRA DE ZOOTECNIA, 38., 2001, Piracicaba. Anais... Piracicaba: Sociedade Brasileira de Zootecnia, 2001. p.373-375.

ROSA, B.; REIS, R.A.; RESENDE, K.T. et al.Valor nutritivo do feno de Brachiaria decumbens Stapaf cv. Basilisk submetido a tratamento com amônia anidra ou uréia. Revista Brasileira de Zootecnia, v.27, n.4, p.809-814, 1998.

SARMENTO, P.; GARCIA, R.; PIRES, A.J.V. et al. Tratamento do bagaço de cana-de-açúcar com uréia. Revista Brasileira de Zootecnia, v.28, n.6, p.1203-1208, 1999.
SILVA, D.J. Análise de alimentos: métodos químicos e biológicos. Viçosa, MG: Universidade Federal de Viçosa, 1990. 165p.

UNIVERSIDADE FEDERAL DE VIÇOSA - UFV. SAEG Sistema de análises estatísticas e genéticas. Versão 8.0. Viçosa, MG: 1998. 150p. (Manual do usuário).

Recebido em: 15/07/02

Aceito em: 03/02/03 